\title{
The training of obstetric physicians and nurses to change the obstetric model in Brazil: A view of the preceptors in the training process
}

\author{
Elisabete M.P. de Carvalho*1,2, Leila B.D. Göttems², Fábio F. Amorim² ${ }^{2}$, Dirce B. Guilhem ${ }^{1}$ \\ ${ }^{1}$ Universidade de Brasilia, Brasília, Brazil \\ ${ }^{2}$ Escola Superior de Ciências da Saúde, Brasília, Brazil
}

Received: May 31, 2020

DOI: 10.5430/jnep.v10n11p15
Accepted: July 12, 2020

Online Published: July 22, 2020

URL: https://doi.org/10.5430/jnep.v10n11p15

\begin{abstract}
Background and objective: In obstetrics training, there are gaps in the scientific evidence on how to teach safe practices with respect. The objective of this study was to explore from the point of view of the preceptors how the process of training obstetricians (physicians and nurses) in residency leads to the development and inculcation of the practices recommended by the national and international guidelines for assistance with natural childbirth.

Methods: Qualitative, exploratory-descriptive study. Thirty-five professionals, including 21 physicians and 14 nurses, from a public institution in the Midwest of Brazil participated in the study. Data were collected through face-to-face interviews conducted from March to June 2018. They were categorized into emerging themes, supported by NVivo to natural birth $₫$ software. Two researchers reviewed the data, and by consensus, the identified issues were confirmed.

Results: Of the participants' comments, 4 themes were codified: approach of the good practices in natural childbirth care; unnecessary practices that remain in use; norms and routines in natural childbirth care; and work processes in the obstetric residency program.

Conclusions: The results highlight the necessity of reorganization of the work processes in the residency program, with continuous action directed toward the strengthening of pedagogical processes and the qualification of the actors involved in the formation and organization of childbirth care services to expand the disruptive potential of new health professionals.
\end{abstract}

Key Words: Professional training, Internship and residency, Natural childbirth care, Evidence-based practice

\section{INTRODUCTION}

The current era is one of intense technological revolution worldwide, with the transmission of information and knowledge at an extraordinary speed in a process of globalization with respect to education, culture, economy and politics. However, it is necessary to consider the challenging reality of the Latin American historical context, in which human exclusion continues to be very significant. ${ }^{[1]}$ In this regard, the maternal mortality rates in Brazil are significantly higher than those observed in developed countries.

The maternal mortality ratio (MMR) is an indicator of human, economic and social development and the quality of health care in a country or region. ${ }^{[2]}$ Based on this understanding, the reduction in maternal mortality was included as one of the goals to be achieved within the Millennium Development Goals (MDGs) 2000-2015 and later in the Sustainable De-

*Correspondence: Elisabete M.P. de Carvalho; Email: elisabete.mesquita29@gmail.com; Address: Universidade de Brasilia, Brasília, Brazil. 
velopment Goals (SDGs) for the years 2016 and 2030. ${ }^{[3]}$ Currently, the global MMR is approximately 210 deaths per 100,000 live births (LB), and all countries must participate in efforts to reduce this MMR by at least two-thirds. In the case of Brazil, the target for 2030 is to reduce to approximately 20 deaths per 100,000 LB. $^{[2,4]}$

To reach this goal, it is necessary to change the model of attention given to childbirth, which is an issue that has been long debated in Brazil and throughout the world. ${ }^{[5]}$ Models of women-centered care have been developed in different countries and in maternity care settings in the US, New Zealand and Scotland, Sweden, Iceland and South Africa. These models are generally designed to limit the number of interventions and to provide information that allows women to make their own care choices based on the premise that pregnancy and childbirth are natural life events. ${ }^{[6]}$

In Brazil, the health system got used to a vicious model and the cesarean section is an escape route for women. According to the World Health Organization, ${ }^{[7]}$ the latest data from 150 countries indicate that Latin America and the Caribbean currently have the highest cesarean rates $(40.5 \%)$, followed by North America (32.3\%), Oceania (31.1\%), Europe (25\%), Asia (19.2\%) and Africa (7.3\%).

However, a change in this model of attention to childbirth and birth, which is currently characterized by intense medicalization, unnecessary interventions and abusive cesarean practices, is already in progress due to the inseparability of the ways of care, management and teaching practices. ${ }^{[8,9]}$ Among these challenges, the training of obstetricians and nurses in the residency modality is one of the main strategies to improve the quality of care for women during pregnancy, childbirth and postpartum.

Professional health training in Brazil has been guided by the traditional model, which is biological, hospital-centered and physician-centered and is based on a specialized and fragmented practice of health care. In this model, priority is given to superspecialization and sophistication of procedures, while pedagogical strategies based on problem-based teaching and the construction of collective knowledge are ignored. ${ }^{[10,11]}$

Health professional education around the world varies with respect to educational standards, curricula and assessment methods and has received much attention in the international literature. ${ }^{[12,13]}$ Ongoing training is an expected part of the fulfillment of the current developmental requirements of health professionals through educational processes, based on the health needs of the population, the family and the user that must be satisfied to meet their expectations regarding health services and professionals. ${ }^{[13]}$

The residency as lato sensu postgraduate education is developed in a regime of full dedication, in which professionals are in permanent contact with the practice of the service, integrating teaching, assistance, theory and practice in their training for life and for the job market. It is considered a differentiated professional qualification, since it allows for the development of professional knowledge and skills and adds security to the development of work and satisfaction with the profession. ${ }^{[14,15]}$

In the context of training in obstetrics, in the residency modality in Brazil, the medical residency and health professional areas (uniprofessional_obstetric nursing) are distinguished. Both are teaching modalities at the lato sensu postgraduate level, characterized by in-service training and supervised by qualified professionals. ${ }^{[14]}$ In this way, they combine pedagogical programs with the arrangements resulting from the integration of teaching and service, which implies tremendous ambiguity in their potential for change in the delivery model: they can be both disruptive and reproductive of current practices.

The preceptors of the residency programs, who act as mediators in the learning process, are capable of provoking reflections and criticisms about the model of assistance provided to women, thus contributing to the necessary advances in the training of new professionals. ${ }^{[16]}$ Thus, considering the potential of the training process in the change of the obstetric model and in the reduction of maternal and neonatal morbidity and mortality, this study aims to explore from the point of view of the training actors how the process of obstetric training (for physicians and nurses) in the modality of residency develops and teaches the practices recommended by the national and international guidelines for natural childbirth care.

\section{Methods}

\subsection{Study design}

This was a qualitative, exploratory-descriptive study conducted from the participant's comments of a public institution of higher education. The qualitative approach allows us to uncover social processes that are not yet well known, provide new approaches, and revise and create new concepts during research, which and can lead to important results on social reality. ${ }^{[17]}$ Qualitative research is typically based on small samples purposely chosen, which favors, as an advantage, the possibility of selecting the most significant cases, according to the study theme, to be able to deepen and access aspects of fundamental importance for the study in question. ${ }^{[18]}$ 


\subsection{Research scenario}

The research was carried out with the preceptors of a higher education institution in the Midwest of Brazil called the School of Sciences of Health. This educational institution adopts problematizing methodologies as the basis for the development of its pedagogical political project, which has as the main axis the construction of knowledge, work in small groups, self-directed learning and the exercise of the dialectical trajectory of action-reflection-action. The construction of these spaces of teaching and learning is of a collective and participatory nature and requires horizontal relationships among the actors (preceptors, tutors, managers, students, health staff, users and community), who value reflection and encourage actions of humanization and integrality of care. ${ }^{[19]}$

The Federal District Secretary of Health, in Brazil, offers medical and nursing residency vacancies in seven hospitals in its health network. Annually are offered, through a selection process, 15 vacancies for Obstetric Nursing (ON) and 102 vacancies for physicians. To supervise the training process there are 79 preceptors: 15 for ON and 64 physicians.

\subsection{Participants}

Individual semi structured interviews were conducted with 35 professionals, of whom 21 were physicians and 14 were nurses (registered obstetric nurse). The sample was non probabilistic and was characterized by criteria of convenience. ${ }^{[20]}$ As a parameter of sample saturation, the exhaustion of new subjects in the respondents' speech was used. ${ }^{[18]}$ The in clusion criteria of the participants were as follows: to be a physician and/or nurse, to act as preceptor and/or supervisor and/or tutor of the obstetric residency medical or nursing courses of the research institution and to agree to participate in the research.

The interviews had an average duration of thirty minutes and were previously scheduled according to the availability of the professional (local and time) and included open-ended questions based on the theoretical framework and the scope of the study. Individual open-ended interviews allowed professionals to speak spontaneously and without restraint or prejudice about their experiences in training.

\subsection{Data collection}

Data collection took place between March and June 2018. The interviews were conducted with a semi structured script and were later transcribed by the main investigator. Before the interview began, the participants signed the Informed Consent Term (TCLE).

Published by Sciedu Press

\subsection{Data analysis}

For the data analysis, consecutive readings of the verbalizations, including cuts of the content of the text and the structure of the information collected, were performed. Transcripts were made shortly after the interviews ended, with the objective of capturing the important elements, including nonverbal ones, that the researcher perceived during the interview and that could help in the analysis process. The respondents were anonymized, and any and all references that could lead to the interviewee's identification were hidden. ${ }^{[21]}$ All participants were described by their professional category ( $\mathrm{P}=$ physician and $\mathrm{N}=$ nurse) followed by a cardinal number (e.g., N1 or P1).

For the treatment of the interviews, an approach to communication analysis called the $\operatorname{Bardin}^{[22]}$ techniques was used for content analysis, which was developed in three stages: 1) pre-analysis, which consisted of the previous reading and organization of the testimonials; 2) exploration of the material, which included the rereading and grouping of the text into pre-established categories; and 3) treatment and interpretation of the data, which allowed for inferences to be made about the contents obtained in the interviews. ${ }^{[17,22]}$

The content analysis process was performed using NVivo $\mathbb{R}$ 13 software, which could support the use of qualitative data analysis. After the creation of the first dataset, the material was explored with exhaustive readings of the transcriptions, with the objective of creating a synthesis of the central ideas that allowed for the identification of the "units of record" and the generation of nuclei of meaning, or so-called "knots" (termed "categories" in NVivo $囚$ ).

For the structuring of the analysis themes, we tried to create representative names that supported the research objective, the guiding question and the theoretical basis. This stage was conducted with the purpose of thoroughly examining what was narrated, elucidating the context in full, and identifying verbalizations and thematic areas. With the data coded and organized into themes, the last stage of the analysis began, which was the interpretation of the results.

\subsection{Ethical considerations}

This study followed the determinations of Resolution No. 466/2012 of the National Health Council, which provides guidelines and norms regulating research involving human beings in Brazil. The project was approved by the Research Ethics Committee of the State Department of Health of the Federal District-CEP/SES/DF under the CAAE number 66007416.3.0000.5553. 


\section{RESUlts}

\subsection{Participant characteristics}

Among the participants $(\mathrm{n}=35), 40 \%$ were nurses and $60 \%$ physicians. Gender wise, $74.28 \%$ were female and $25.72 \%$ male. The average age of this group was 45 years old; the time of academic training was 20 years and working in the preceptorship, 8 years of experience.

Based on the speeches, 4 themes and 10 categories were coded for the perception of the training preceptors in the residency modality regarding national and international scientific production and the public policies related to the researched topic. Table 2 presents the themes and categories identified.

Table 1. Characteristics of respondents (gender, age, time since graduation and time of preparation). Brasilia, 2020

\begin{tabular}{lllll}
\hline & Preceptors profile & Physicians $(\mathbf{n}=\mathbf{2 1})$ & Nurses $(\mathbf{n}=\mathbf{1 4})$ & Total $(\mathbf{n}=\mathbf{3 5})$ \\
\hline Gender & Male & 8 & 1 & 9 \\
& Female & 13 & 13 & 26 \\
Age (years) & $<30$ & & 2 & 2 \\
& $30-45$ & 8 & 10 & 18 \\
& $>45$ & 13 & 2 & 15 \\
Graduate & 10 & 1 & 2 & 3 \\
Time (years) & $10-30$ & 18 & 12 & 30 \\
& $>30$ & 2 & & 2 \\
Preceptorship & $3-10$ & 1 & 4 & 5 \\
Time (years) & $>10$ & 12 & 9 & 21 \\
\hline
\end{tabular}

Table 2. Themes, categories and comments indicated by participants

\begin{tabular}{|c|c|c|}
\hline Themes & Categories & Comments \\
\hline \multirow{2}{*}{$\begin{array}{l}\text { Approach of good } \\
\text { practices of } \\
\text { attention to natural } \\
\text { birth }\end{array}$} & $\begin{array}{l}\text { Alignment between theory and } \\
\text { practice }\end{array}$ & $\begin{array}{l}\text { “...in fact, what we are looking for is an alignment between theoretical } \\
\text { content and practice."(N8) }\end{array}$ \\
\hline & Demonstratively useful practices & $\begin{array}{l}\text { “(...)Good practices are addressed in lectures and practical } \\
\text { classes.” }(P 11)\end{array}$ \\
\hline \multirow{3}{*}{$\begin{array}{l}\text { Unnecessary } \\
\text { practices that remain } \\
\text { in natural childbirth } \\
\text { care }\end{array}$} & Clearly harmful practices & $\begin{array}{l}\text { "Enema and trichotomy, we do not do it anymore, I cannot even think } \\
\text { of a place that still does it."(N3) }\end{array}$ \\
\hline & $\begin{array}{l}\text { Practices without evidence that } \\
\text { should be used with caution }\end{array}$ & $\begin{array}{l}\text { "Today, there is no more routine induction (...)”(N7) } \\
\text { "The Kristeller maneuver is rare, but it is still happening."(N11) }\end{array}$ \\
\hline & Improperly used practices & $\begin{array}{l}\text { "In the nursing residency, we abolished the episiotomy; it is not } \\
\text { done."(N2) }\end{array}$ \\
\hline \multirow{3}{*}{$\begin{array}{l}\text { Norms and routines } \\
\text { in assisting natural } \\
\text { childbirth }\end{array}$} & Lack of a written standard & “No, written rules, I do not know.”(N11) \\
\hline & Use of the unit protocol & $\begin{array}{l}\text { "There is an obstetrical protocol that was done by the previous } \\
\text { preceptors."(P8) }\end{array}$ \\
\hline & $\begin{array}{l}\text { Use of the norms of the Ministry } \\
\text { of Health }\end{array}$ & "Here, we have adopted the manuals of the Ministry of Health."(P11) \\
\hline \multirow{2}{*}{$\begin{array}{l}\text { Work processes in } \\
\text { the obstetric } \\
\text { residency scenario }\end{array}$} & $\begin{array}{l}\text { Low risk attended by obstetric } \\
\text { nursing }\end{array}$ & $\begin{array}{l}\text { "(...)the doctors are aware of the division; if it is low risk, they know it } \\
\text { is nursing, the priority is nursing; if it is high risk...(...)"(N1) }\end{array}$ \\
\hline & Not systematized & $\begin{array}{l}\text { "I think this (is) not yet solved; I worry a lot about enough experience } \\
\text { for everyone."(P3) }\end{array}$ \\
\hline
\end{tabular}

\subsection{Approach of good practices of attention to childbirth and birth in the programs of nursing and medical residency}

From the speeches of the interviewees, we sought to identify how best practices are discussed in the residency program.
What is used? How is it used? Who is it used by?

"We end up showing in practice how it is done and then we discuss in theory why it is done that way (...). So, it is done in practice and in theory." (N1O)

"One of the first modules of the theoretical program of medi- 
cal residency is childbirth care, and within this module, they have all the items related to good childbirth care practices, and in addition, during the practical activity, the theoretical part is put into practice. (The information) is seen in theory and (in practice).” (P1)

In the Demonstratively Useful Practices category, preceptors reported safe practices based on scientific evidence presented at the time of obstetric clinical practice with residents.

Table 3. Main demonstratively useful practices cited by the respondents

\begin{tabular}{|c|c|c|c|c|}
\hline \multirow{3}{*}{ Demonstratively useful practices } & \multicolumn{4}{|c|}{ Frequency } \\
\hline & \multicolumn{2}{|c|}{ Nurses } & \multicolumn{2}{|c|}{ Physicians } \\
\hline & $\mathbf{N}^{\mathbf{0}}$ & $\%$ & $\mathbf{N}^{\mathbf{0}}$ & $\%$ \\
\hline Nonpharmacological methods of pain relief & 14 & 100.0 & 13 & 61.9 \\
\hline Presence of companion & 11 & 78.5 & 16 & 76.1 \\
\hline Ambulation & 13 & 92.8 & 8 & 38.0 \\
\hline Freedom of position and movement & 11 & 78.5 & 8 & 38.0 \\
\hline Timely cord clamping/skin-to-skin contact/breastfeeding at 1 hour postpartum & 5 & 35.7 & 8 & 38.0 \\
\hline Alternative childbirth positions & 8 & 57.1 & 4 & 19.0 \\
\hline Food and liquids during labor & 5 & 35.7 & 9 & 42.8 \\
\hline Support & 6 & 42.8 & 3 & 14.3 \\
\hline
\end{tabular}

Table 3 represents the quantification of responses in order of recurrence on the main demonstrably useful practices cited by the respondents. Non-pharmacological methods of pain relief were the most cited, both by nurses and doctors. The presence of a companion was the second most cited practice by respondents. Ambulation, a non-pharmacological method that promotes greater tolerance of the parturient regarding pain in labor, was the third most cited practice. Freedom of position and movement, timely cord clamping, skin-to-skin contact, breastfeeding in the first postpartum hour, alternative positions in childbirth, use of food and liquids during labor and delivery and emotional support/support were also mentioned.

\subsection{Unnecessary practices that remain in childbirth care}

The intention was to verify which practices were abolished and which remain in use in delivery assistance. The interviewees noted the following modalities:

"Directed pushing efforts are still widely used by doctors and nursing." (P9)

"Kristeller is rarely used, because people are looking with an ugly face when doing Kristeller ... then people are thinking twice before doing Kristeller, only in acts of desperation." (P4)

"It's very difficult, really, in a teaching scenario in which there are a lot more touches because you are in the process of teaching (...). So, invariably, in a service with this profile, there turn out to be a greater number of touches than expected in relation to best practices." (P4)

Published by Sciedu Press

\subsection{Norms and routines in natural childbirth care}

We sought to identify the existence of written norms regarding childbirth assistance practices. There was evidence of a lack of consensus among the participants related to this theme.

"Written rules, we don't have!" (N12)

"It is in the process of being done, almost ready. But it does not yet exist." (P19)

"We use the rules of the Ministry of Health, which are written standards...to guide and orientate public services, so we do not need to reinvent the wheel." (P5)

\subsection{Residency work processes in the setting of childbirth care}

We sought to identify how the delivery scenario is managed with physicians and nursing residents. It has been shown that in certain services, there are clear divisions of work processes, such that nursing accompanies low-risk deliveries and medicine accompanies high-risk deliveries. However, there are other services in which this process is not systematic. It was emphasized that the quantitative of nursing preceptors is still very low in all scenarios investigated.

"There is no separation of low-risk and high-risk patients so far (...) we are proposing that low-risk deliveries should be performed with obstetric nursing and other deliveries with medical and internal medical staff, but there is no such definition yet." (N12)

"There is no way to talk about dividing patients..." (P9) 


\section{Discussion}

\subsection{Search for the alignment between theory and prac- tice}

Nursing and medical residency programs seek the alignment of theory and practice, from the classroom to practice scenarios. Thus, they rely on the ability of the preceptor, ${ }^{[23]}$ whose knowledge must transcend technical skills for adequate and timely care. ${ }^{[24]}$ The scientific literature has broadly presented ample evidence that supports the importance of good preceptorship in obstetrics. ${ }^{[25]}$

For Lima et al., ${ }^{[14]}$ the collective and shared construction of pedagogical work in residential training, with the intense participation of residents, preceptors, teachers, service professionals, managers and parturients, has the greatest disruptive potential to this type of training. In the teaching of obstetric care, this articulation contributes to overcoming the differences between knowledge and the roles exercised by the actors of the institutions in the formation process.

In this study, the participants mentioned a fundamental quality of the professional development of the resident: the incorporation of scientific evidence into clinical practice. Among the practices in use in health services, they mentioned the presence of companion, nonpharmacological methods of pain relief, breastfeeding in the first hour of life, skin-to-skin contact, timely cord clamping, and freedom of movement position, among other possibilities. This finding was consistent with the results of Côrtes et al. ${ }^{[26]}$

According to Leal, ${ }^{[27]}$ the presence of nursing in childbirth care is associated with better results in obstetric clinical practice, with the use of non-pharmacological pain relief methods, reduction of unnecessary interventions, women's satisfaction with the care received and positive perinatal outcomes.

The World Health Organization envisions a world in which all women receive quality care during pregnancy, childbirth and postpartum. It is believed that with the adoption of an evidence-based approach, unnecessary practices will be abandoned, rates of maternal and neonatal morbidity and mortality will be minimized, and women will enjoy positive experiences related to childbirth and birth. ${ }^{[28,29]}$

In a systematic review of qualitative studies ${ }^{[7]}$ it was identified that women want emotional support and want to be informed of and participate in decision making regarding the birth of their children. The teaching of these aspects depends on the ability of the preceptor to enable the resident to understand when interventions become necessary because of valid indications, and above all, that the patient must be aware of the need and the risks through informed consent. ${ }^{[30]}$

\subsection{Unnecessary practices that remain in childbirth care}

The interviewees noted that some clearly harmful practices remain in use in the daily care services of childbirth and birth, such as lithotomy, directed pushing efforts, and frequent vaginal touches (and by more than one professional). Other practices, such as routine episiotomy, hydration, routine oxytocin and the Kristeller maneuver (consists of compressing the uterine fundus during the second period of labor, aiming at its abbreviation), are increasingly rare in deliveries. The enema (intestinal cleanser) and the trichotomy (scraping of pubic hair) have been completely abolished. It is known that unnecessary interventions performed without indications hinder the natural progression of labor, causing complications to the fetus and the mother. ${ }^{[28]}$ Studies in Latin American countries, the Caribbean, Canada, Spain, China, South Africa and Turkey have indicated that unnecessary medical interventions are common during natural birth. ${ }^{[28,31]}$

Advances in medical technologies have undeniably contributed significant benefits to maternal and child health, especially in high-risk pregnancies and premature births. However, the indiscriminate use of unnecessary interventions without evidence-based indications compromises the physiology of birth and contributes to the occurrence of iatrogenies. ${ }^{[28]}$

For Symon et al., ${ }^{[32]}$ the incorporation of respectful and individualized care values and respect for physiological processes are essential to the high quality of care provided. The philosophy and practice of obstetric nursing, with an emphasis on holistic person-centered approaches, are particularly suited to the changing needs of populations around the world. $^{[33]}$

Obstetrical nurses have a profile and competence for the use of light technologies in assisting the physiological process of birth, contributing to its natural evolution, recognizing and correcting deviations from normality, and referring those who demand specialized assistance. They propose care that allows for a permanent commitment of the professional, such as bond accountability, leading to greater attention resolution. ${ }^{[34]}$

\subsection{Nonexistence of a unit protocol}

More than $50 \%$ of the respondents reported that they did were not aware of the existence of written norms guiding the practices of attention to natural childbirth, which corroborates the lack of definition in the team's work processes. For Leal, ${ }^{[27]}$ the low implementation of clinical protocols is reported worldwide and may be associated with the characteristics of the clinical protocol itself, the healthcare professional, the patient, the external environment, among other causes. 
For Koblinsky, ${ }^{[35]}$ despite the diversity of care models, the starting point is the same for all countries: to ensure that every woman in any location is placed in a safe environment, each country needs clear norms regarding the care that should be provided to women in the pregnancy-puerperal cycle.

For Lopes et al., ${ }^{[36]}$ evidence shows that being born in Normal Childbirth Center, in a hospital with a collaborative model, in an institution with standardized protocols, or having a midwife-assisted delivery increases the chances of women and their newborns have access to good practices and reduces the chances of harmful and unnecessary interventions.

In an attempt to describe childbirth practices in Brazil, the Ministry of Health published the ordinance 353/2017 in 2017 approving the National Guidelines for Assistance to Natural Childbirth. ${ }^{[37]}$ These guidelines should be adopted by the state and municipal authorities that assume responsibility for structuring the care network, defining referral services and establishing the flows for the care of pregnant women at all stages of care. They seek to subsidize the systematic evaluation through available scientific information regarding the most common practices in their assistance with childbirth.

\subsection{Absence of systematization in work processes}

According to the participants' comments, the work process in the obstetric residency scenario is not clearly organized and requires attention, specifically in the construction of flows for the formalization of these processes. As noted by Symon et al., ${ }^{[32]}$ having strong organizational management and support is a vital factor for any organization, but particularly for those that are introducing innovative approaches.

Organizational support is central to improving the resident training process, as the challenges include extrapolating the acquisition of technical and scientific knowledge related to a profession, reducing the fragmentation of health knowledge and practices, and changing established ways of producing health care through the joint actions of training and managing health services. ${ }^{[38]}$

The current study provides evidence for clinical practice, training of new professionals and other researches. It confirms that obstetric nurses, when implement the light technologies of care, decrease the unnecessary interventions to natural birth and improve the access of women to best practices as shown in Table 3. In addition, the results reinforce that the process of training new obstetricians, based on the appropriate use of light technologies, combined with wellconducted public policies constitute a major transformative force in the model of care for childbirth and labor birth. Furthermore, the results demonstrate the methodology of training to new clinical practices must be itself an object of new researches to assess and innovate it. The limitations of this research are related to the absence of pediatricians and anesthesiologists because these medical specialties don't act as preceptors in the residency programs studied. We suggest for the improvement of residency programs that these specialties can also be trained and incorporated as preceptors.

\section{Conclusion}

Collaborative efforts among trainers, researchers, health professionals, and management are central to the successful implementation of best practices for natural childbirth that are addressed both in theory and clinical practice. The absence of systematization in the work processes identified in this study constitutes a limitation in the development of essential skills of residents, especially those in nursing. The teaching in the residency program requires continuous attention and directed toward the strengthening of the pedagogical processes, the qualification of the actors involved in the formation and the organization of the childbirth services to amplify the disruptive potential of the new health professionals.

\section{CONFlicts OF INTEREST Disclosure}

The authors declare no conflict of interest.

\section{REFERENCES}

[1] Severino AJ. Humanismo, Personalismo e os desafios sociais da educação contemporânea. Revista de Educação Pública. 2012; 18(36): 155-163. https://doi.org/10.29286/rep.v18i36.528

[2] Souza JP. Maternal mortality and the new objectives of sustainable development (2016-2030). Revista brasileira de ginecologia e obstetricia: revista da Federacao Brasileira das Sociedades de Ginecologia e Obstetricia. 2015; 37(12): 549-551. PMid:26647842 https://doi.org/10.1590/S0100-720320150005526

[3] Sustainable Development Goals. New York: United Nations; 2015. Available from:https://sustainabledevelopment.un. org/?menu=1300

[4] World Health Organization. Strategies toward ending preventable maternal mortality (EPMM). 2015. Available from: http://who.int/reproductivehealth/topics/maternal _perinatal/epmm/en/

[5] Pereira RM, de Oliveira Fonseca G, Pereira ACCC et al. New childbirth practices and the challenges for the humanization of health care in southern and southeastern Brazil. Ciencia \& Saude Coletiva. 2018; 23(11): 3517-3525. PMid:30427425 https://doi.org/10.159 0/1413-812320182311.07832016

[6] Lundgren I, Berg M, Nilsson C, et al. Health professionals' percep- 
tions of a midwifery model of woman-centred care implemented on a hospital labour ward. Women and Birth. 2020; 33(1): 60-69. PMid:30686654 https://doi .org/10.1016/j . wombi.2019.0 1.004

[7] World Health Organization. Recommendations non-clinical interventions to reduce unnecessary caesarean sections. 2018. Available from: https://apps.who.int/iris/bitstream/handle/106 65/275377/9789241550338-eng.pdf

[8] Betrán AP, Temmerman M, Kingdon C, et al. Interventions to reduce unnecessary caesarean sections in healthy women and babies. The Lancet. 2018; 392(10155): 1358-1368. https://doi.org/10.1 016/S0140-6736(18) 31927-5

[9] Boerma T, Ronsmans C, Melesse DY, et al. Global epidemiology of use of and disparities in caesarean sections. The Lancet. 2018; 392(10155): 1341-1348. https://doi.org/10.1016/S0140-6 736 (18) 31928-7

[10] Moraes BA, Costa NMDS. Understanding the curriculum the light of training guiding health in Brazil. Revista da Escola de Enfermagem da USP. 2016; 50(SPE): 9-16. PMid:27384270 https: //doi.org/10.1590/S0080-623420160000300002

[11] Meneses JRD, Ceccim RB, Martins GC, et al. Residências em saúde: os movimentos que as sustentam. Formação de formadores para residências em saúde: corpo docente-assistencial em experiência viva [recurso eletrônico] Porto Alegre: Rede UNIDA. 2018; p. 33-48. Available from: https://www.lume.ufrgs.br/bitstream/ha ndle/10183/179754/001069687.pdf? sequence=1

[12] Greig A, Dawes D, Murphy S, et al. Program evaluation of a model to integrate internationally educated health professionals into clinical practice. BMC medical education. 2013; 13(1): 140. PMid:24119470 https://doi.org/10.1186/1472-6920-13-140

[13] Lawn S, Zhi X, Morello A. An integrative review of e-learning in the delivery of self-management support training for health professionals. BMC medical education. 2017; 17(1): 183. PMid:29017521 https://doi.org/10.1186/s12909-017-1022-0

[14] Lima GPV, Pereira ALF, Guida NFB, et al. Expectations, motivations and perceptions of nurses on the nurse-midwifery specialization course in the residence modality. Esc Anna Nery Rev Enferm. 2015; 19(4). https://doi.org/10.5935/1414-8145.20150079

[15] Oliveira Silva RM, Cordeiro ALAO, Fernandes JD, et al. Contribution of a residency specialization program to professional knowhow. Acta Paulista De Enfermagem. 2014; 27(4): 362. https: //doi.org/10.1590/1982-0194201400060

[16] Canever BP, do Prado ML, Gomes DC, et al. Self-knowledge of health teachers: a qualitative exploratory study. Nurse Education Today. 2018; 65: 54-59. PMid:29525487 https ://doi.org/10.1 016/j.nedt. 2018.02.035

[17] Minayo MCS. O desafio do conhecimento: pesquisa qualitativa em saúde. 4ed. Hucitec: São Paulo. 2014.

[18] Flick U. Pesquisa qualitativa e quantitativa. Introdução à Pesquisa Qualitativa. Tradução Costa, JE 3ed. Porto Alegre: Artmed, 39-49. 2009.

[19] GDF. Secretaria de Estado de Saúde do DF. Fundação de Ensino e Pesquisa em Ciências da Saúde. Relatório de Atividades 2018. Brasília.

[20] Vergara SC. Projetos e relatórios de pesquisa em administração. 11a. ed. São Paulo: Atlas, 2009.

[21] Lima JLO, Manini MP. Metodologia para Análise de Conteúdo Qualitativa integrada à técnica de Mapas Mentais com o uso dos softwares Nvivo e FreeMind. Informação \& Informação, 21(3): 63-100. https://doi.org/10.5433/1981-8920.2016v21n3p63

[22] Bardin L. Análise de Conteúdo. São Paulo: Edições 70, 223p. 2011.
[23] Gismalla MDA, Kaliya-Perumal AK, Habour AB, Mohammed MEI. Does perception of clinical competency correlate with perception of training efficiency? Journal of Medical Education. 2017; 16(4): 221-226. Available from: http://repo.uofg.edu.sd/handle/ $123456789 / 746$

[24] Campbell OM, Calvert C, Testa A, et al. The scale, scope, coverage, and capability of childbirth care. The Lancet. 2016; 388(10056): 2193-2208. https://doi.org/10.1016/S0140-6736(16) 315 28-8

[25] Lukasse M, Lilleengen AM, Fylkesnes AM, Henriksen L. A opinião das parteiras norueguesas sobre sua educação em obstetrícia - um estudo de métodos mistos. BMC medical education. 2017; 17(1): 80. PMid:28468617 https://doi .org/10.1186/s12909-017-091 7-0

[26] Côrtes CT, Oliveira SMJVD, Santos RCSD, et al. Implementation of evidence-based practices in normal delivery care. Revista latino-americana de Enfermagem. 2018; 26. PMid:29538583 https: //doi.org/10.1590/1518-8345.2177.2988

[27] Leal MDC, Bittencourt SDA, Esteves-Pereira AP, et al. Progress in childbirth care in Brazil: preliminary results of two evaluation studies. Cad. Saúde Pública. 2019; 35(7):e00223018. PMid:31340337 https://doi.org/10.1590/0102-311X00223018

[28] Çalik KY, Karabulutlu Ö, Yavuz C. First do no harm-interventions during labor and maternal satisfaction: a descriptive crosssectional study. BMC pregnancy and childbirth. 2018; 18(1): 415. PMid:30355293 https://doi.org/10.1186/s12884-018-205 4-0

[29] Miller S, Abalos E, Chamillard M, et al. Beyond too little, too late and too much, too soon: a pathway towards evidence-based, respectful maternity care worldwide. The Lancet. 2016; 388(10056), 2176-2192. https://doi .org/10.1016/S0140-6736(16)31472-6

[30] Jansen L, Gibson M, Bowles BC, Leach J. First do no harm: interventions during childbirth. The Journal of perinatal education. 2013; 22(2): 83-92. PMid:24421601 https://doi.org/10.1891/1058 $-1243.22 .2 .83$

[31] Binfa L, Pantoja L, Ortiz J, et al. Midwifery practice and maternity services: A multisite descriptive study in Latin America and the Caribbean. Midwifery. 2016; 40: 218-225. PMid:27476027 https://doi.org/10.1016/j.midw . 2016.07.010

[32] Symon A, Pringle J, Cheyne H, et al. Midwifery-led antenatal care models: mapping a systematic review to an evidence-based quality framework to identify key components and characteristics of care. BMC pregnancy and childbirth. 2016; 16(1): 168. PMid:27430506 https://doi.org/10.1186/s12884-016-0944-6

[33] Crisp N. Nursing and Midwifery: Key to Implementing AlmaAta 40 Years on. Health Systems \& Reform. 2018; 4(3): 183187. PMid:30081706 https://doi.org/10.1080/23288604.2 018.1483683

[34] Gramacho RCCV, Silva RCV. Enfermagem na cena do parto. In: Brasil. Humanização do parto e nascimento. Brasília (DF): Ministério da Saúde. 2014; 4: 184-200. (Cadernos Humaniza SUS).

[35] Koblinsky M, Moyer CA, Calvert C, et al. Quality maternity care for every woman, everywhere: a call to action. The Lancet. 2016; 388(10057): 2307-2320. https://doi.org/10.1016/S0140-6 736 (16) 31333-2

[36] Lopes GC, Gonçalves AC, Gouveia Helga G, et al. Attention to childbirth and delivery in a university hospital: comparison of practices developed after Network Stork. Rev. Latino-Am. Enfermagem. 2019; 27: e3139. PMid:31038633 https://doi .org/10.1590/1518-8 345. 2643-3139 
[37] Brasil, Ministério da Saúde. Secretaria de Atenção à Saúde. Portaria $\mathrm{n}^{\mathrm{o}} 353$, de 14 de fevereiro de 2017. DOU de 20/02/2017 ( $\mathrm{n}^{\mathrm{o}} 36$, Seção 1, pág. 37).

[38] Heckert ALC, Neves CAB. Modos de formação e modos de inter- venção: Quando uma formação se faz poderosa de produção de coletivo. In: Brasil, Política Nacional de Humanização: Formação e intervenção. Ministério da Saúde, Brasília, 1, 13-28. (Cadernos Humaniza SUS). Available from: http://bvsms . saude.gov.br /bvs/publicacoes/cadernos_humanizaSUS.pdf 